\title{
The Resource Based View of IT Business Value: Complementary Investments or Embedded Knowledge?
}

\author{
Vishnu Vinekar \\ Fairfield University, vvinekar@fairfield.edu
}

J.T.C. Teng

Follow this and additional works at: https://digitalcommons.fairfield.edu/business-facultypubs Preprint of an article submitted for consideration in Journal of Information \& Knowledge Management (C) 2012 copyright World Scientific Publishing Company. http://www.worldscinet.com/jikm/jikm.shtml

\section{Repository Citation}

Vinekar, Vishnu and Teng, J.T.C., "The Resource Based View of IT Business Value: Complementary Investments or Embedded Knowledge?" (2012). Business Faculty Publications. 46.

https://digitalcommons.fairfield.edu/business-facultypubs/46

\section{Published Citation}

Vinekar, Visnu \& Teng, J.T.C (forthcoming-[2012]) The Resource Based View of IT Business Value: Complementary Investments or Embedded Knowledge? Journal of Information and Knowledge Management. [Vol.11, issue 1].

This item has been accepted for inclusion in DigitalCommons@Fairfield by an authorized administrator of DigitalCommons@Fairfield. It is brought to you by DigitalCommons@Fairfield with permission from the rightsholder(s) and is protected by copyright and/or related rights. You are free to use this item in any way that is permitted by the copyright and related rights legislation that applies to your use. For other uses, you need to obtain permission from the rights-holder(s) directly, unless additional rights are indicated by a Creative Commons license in the record and/or on the work itself. For more information, please contact digitalcommons@fairfield.edu. 


\section{Editorial Manager(tm) for Journal of Information and Knowledge Management}

Manuscript Draft

Manuscript Number:

Title: THE RESOURCE-BASED VIEW OF IT BUSINESS VALUE: COMPLEMENTARY INVESTMENTS OR EMBEDDED KNOWLEDGE?

Article Type: Research Paper

Keywords: IT business value; resource-based view; direct effects; interaction effects; knowledge effects

Corresponding Author: Vishnu Vinekar, Ph.D. in Business Administration

Corresponding Author's Institution:

First Author: Vishnu Vinekar, Ph.D.

Order of Authors: Vishnu Vinekar, Ph.D.;Vishnu Vinekar, Ph.D. in Business Administration;James T. C. Teng, Ph.D.

Abstract: In this paper we test a primary postulate of the resource-based theory of IT business value. From this perspective, IT is not rare but pervasive, and it is only the combination of investments with other resources that makes the investment inimitable. Therefore, the effect of IT on firm performance cannot be direct effects, but rather firm performance can only be affected when IT expenditures are combined with other investments. We test this theory using panel data of large firms spanning 7 years. Firm level data is gathered from Compustat and matched to IS Budget data from InformationWeek's annual rankings. We find that no support for the RBV postulate that IT Expenditure cannot have direct competitive advantage but must be combined with expenditure on other assets to effect firm performance. Instead we find support for the opposing hypotheses: IT expenditure and capital expenditures have independent, direct effects on firm revenue as well as firm profit, even in the presence of the interaction variable. The results imply that IT investments may be a source of direct competitive advantage, unlike the postulate of the resource-based view theorists. This may be because an IT system has embedded knowledge and creates knowledge, making it rare and imperfectly imitable. Rather than investing in generic IT systems and trying to obtain uniqueness from investments in complementary resources, firms can try embedding firm-specific knowledge when designing or modifying their systems and using their systems to create knowledge. This is the first study to test the resource-based view's postulate that value from IT comes only with the combination of IT investments and investments in other assets and not from direct effects. By disproving this postulate, we open the door to new hypotheses based on knowledge in and from IT systems. 


\section{Abstract}

In this paper we test a primary postulate of the resource-based theory of IT business value. From this perspective, IT is not rare but pervasive, and it is only the combination of investments with other resources that makes the investment inimitable. Therefore, the effect of IT on firm performance cannot be direct effects, but rather firm performance can only be affected when IT expenditures are combined with other investments. We test this theory using panel data of large firms spanning 7 years. Firm level data is gathered from Compustat and matched to IS Budget data from InformationWeek's annual rankings. We find that no support for the RBV postulate that IT Expenditure cannot have direct competitive advantage but must be combined with expenditure on other assets to effect firm performance. Instead we find support for the opposing hypotheses: IT expenditure and capital expenditures have independent, direct effects on firm revenue as well as firm profit, even in the presence of the interaction variable. The results imply that IT investments may be a source of direct competitive advantage, unlike the postulate of the resource-based view theorists. This may be because an IT system has embedded knowledge and creates knowledge, making it rare and imperfectly imitable. Rather than investing in generic IT systems and trying to obtain uniqueness from investments in complementary resources, firms can try embedding firmspecific knowledge when designing or modifying their systems and using their systems to create knowledge. This is the first study to test the resource-based view's postulate that value from IT comes only with the combination of IT investments and investments in other assets and not from direct effects. By disproving this postulate, we open the door to new hypotheses based on knowledge in and from IT systems.

Keywords: IT business value, resource-based view, direct effects, interaction effects, knowledge effects. 


\section{Introduction}

The business value of Information Technology (IT) has been a central question of Information Systems research. As firm IT Expenditure increased by orders of magnitude from the 1960s to the 1990s (Carr, 2003), IS research has searched for evidence of the expected benefits of this expenditure. According to Melville, Kraemer and Gurbaxani (2004), IT business value is defined as "the organizational performance impacts of information technology at both the intermediate process level and the organization-wide level, and comprising both efficiency impacts and competitive impacts". Researchers have built up a considerable body of literature over the years. The initial debate on the IT productivity paradox (Brynjolfsson, 1993) was resolved with empirical evidence of strong positive relations between IT investments and firm productivity (Hitt \& Brynjolfsson, 1996). However, there is evidence contradicting the implication that productivity benefits lead to an increase in firm profits (Hitt \& Brynjolfsson 1996, Mahmood \& Mann 1993, Peslak 2003). For example, Mahmood \& Mann (1993) find that IT budget negatively affects performance; Hitt \& Brynjolfsson (1996) find a negative relationship between IT Expenditure and firm performance. New theories have emerged recently to explain these conflicting findings, a prominent one in the theoretical literature on IT Business Value is the resource-based view (Bharadwaj, 2000; Melville, Kramer and Gurbaxani, 2004). This view states that the impact of IT on firm performance should not be considered in isolation, but instead should be considered in conjunction with complementary assets of the firm. After this view received attention in the theoretical literature, empirical work in this area has recently started. In addition, although the few empirical studies have attempted to model indirect effects of IT (for example, see Ranganathan \& Brown 2006; Tanriverdi 2006; Zhang 2007), the RBV's postulate that the direct effects of IT do not exist, and that business value is obtained solely through a combination of IT investments and investments in complementary assets has not been tested empirically.

This paper attempts to test this theory with the following research questions: Does firm expenditure on IT have independent effects on firm performance? Or do the effects on firm performance come more through an interaction effect with complementary resources? We address these two research questions by using panel data on large firms over seven years, and find that the effects of both IT and complementary resources are indeed independent and not an interaction effect as the resource based view suggests. 
The remainder of this paper is organized as follows: First, we review the relevant literature and then develop our theoretical framework by building upon these studies. We then specify our research model and hypothesis. We test the hypothesis from a set of panel data on US firms over a seven-year period. Following this, we discuss the results in detail, and explain the contributions to research and practice. Finally, we end with the limitations of this study and directions for future research.

\section{Literature review}

From the very beginning of computer applications in business, the seminal paper by Leavitt \& Whisler (1958) defined the term "information technology" and was among the first to predict the vast contribution that this new technology would have. Since then, a vast literature on the role of IT in creating business value has been developed. In this section, we will summarize the theoretical and conceptual advances, and provide a brief review of empirical works related to this area.

\section{Theoretical and Empirical Research}

Early empirical work in IT business value was developed mostly from the transaction cost economics perspective (Williamson, 1975). Building on this, empirical works suggest that IT does improve productivity (Brynjolfsson 1993). However, although it is implied theoretically that these productivity gains make the firm more profitable, empirical research contradicts this relationship. Hitt \& Brynjolfssonn (1996) were among the first to make the distinction between productivity and profitability. They explicitly stated that these are very different measures and should be studied as such. Although their empirical results show that IT has a strong relationship with productivity, they also find a weak negative relationship with profitability. They argue that this may be because productivity gains are competed away between firms. Therefore, instead of retaining these productivity gains as profits, they are passed on to consumers.

Theory built on the resource-based view believes this postulate; i.e., IT can affect productivity but cannot directly affect firm profit, as IT is copied by other firms and therefore not a source of competitive advantage (Carr, 2003). This view states that sustained competitive advantage comes from resources that are valuable, rare, and imperfectly imitable (Barney 1991). This view states that IT is neither rare nor imperfectly imitable, it cannot be a source of competitive advantage, and therefore cannot increase firm profits. However, RBV theorists believe that 
even though IT Expenditure cannot have direct effects on firm profits, the combination of expenditure on IT and expenditure on other resources can jointly have an effect on profits (Bharadwaj 2000; Melville et al 2004). Melville et al (2004) develop a model of IT Business Value from the resource-based perspective, in which IT is combined with other organizational resources and is deployed within business processes to improve business process performance, which in turn contributes to organizational performance. Melville et al (2004) make a significant contribution in developing an RBV based model. In this model, investing in Information Technology does not create value on its own; rather, the firm has to invest in other resources, and the combination of investments make the organization more productive and profitable. In addition, information systems implementations need considerable organizational change to succeed, including additional investments in other physical assets (Bharadwaj, 2000; Melville, et al, 2004).

Following the theoretical work, a few recent studies have started looking for indirect effects of IT (for example, see Ranganathan \& Brown 2006; Tanriverdi 2006; Zhang 2007). For example, Ranganthan and Brown (2006) indirectly study complementary effect by looking at ERP projects' physical scope and functional scope. They assume that ERP project with greater physical and functional scope will have greater investments in complementary resources, and therefore will have greater competitive advantage. Similarly, Tanriverdi (2006) looks for performance effects synergies between the business units of multibusiness firms investing in IT. Zhang (2007) studies whether certain unique organizational qualities that complement information systems help firm performance and finds that some do while others do not. However, these studies do not test the RBV postulate that the indirect effects overshadow the direct effects of IT on firm performance. This is the central research question of this paper.

There are also some methodological concerns in the empirical literature. Most empirical studies do not incorporate a time lag between IT investment and firm performance. This seems problematic from theoretical as well as empirical standpoints. Theoretically, IT Expenditure tends to require learning periods before benefits are realized. Empirically, studies show that several investments demonstrate benefits only after a time lag. For example, Nicolaou (2004) finds that ERP investments only show benefits two years after implementation. Therefore, in our model, we explicitly consider time lags between IT Expenditure and its effects on firm performance. 


\section{Research Model and Hypothesis}

As seen in the literature review, there are a few gaps in research on Resource Based View models on IT Business Value. The most important of these is that the resource based view of IT Business Value posits that the effects of IT on firm profit are not direct, and can only be affected by combining it with complementary resources. This has not been explicitly tested in the empirical literature. The empirical survey leads us to the further structuring of the model to reflect the intricate time legs. Our model enables us to move further in building up the cumulative research tradition.

As with previous theoretical literature, IT Expenditure can have a positive impact on Firm Revenue. However, the impact of IT on firm revenue needs changes in business processes. For example, Toyota and Dell gained tremendous revenue and profit improvements by switching from mass manufacturing to Just-In-Time. Similarly, Wal-Mart gained these advantages by switching from ordering and shipping in bulk to ordering and shipping only what was sold. These changes required not only the Information technology to enable large quantities of small orders and mass customization, but it also required massive amounts of Business Process Reengineering, including major capital expenditure on changes in the company's physical and organizational resources. Toyota needed to change their plants to accommodate quick die switching instead of storing huge numbers of auto parts, Dell needed to change to a mass customization model to accommodate various permutations and combinations of customer orders, and Wal-Mart had to switch from a model that had large warehouses to replenish sold goods to using only what could be stored on retail shelves and speedy replenishment from tens of thousands of suppliers. Revenue can be greatly improved, however, these require both IT Expenditure as well as simultaneous Capital Expenditures. In the hypotheses following this reasoning, we explicitly incorporate a time lag. This is because the effects of expenditure on IT and Capital Expenditure do not result in immediate improvements. Changes in business processes, organizational structure and strategy take time to show results.

According to the RBV, the effects of IT on Firm Revenue are not direct effects as IT is not rare and inimitable. Therefore, the effect of IT on Firm Revenue does not occur directly, but occurs instead solely through an interaction with spending in capital expenditure. To tests this, we examine the RBV hypothesis against the opposing direct effects hypotheses:

Resource-Based View (RBV) hypothesis: 
H1: IT Expenditure and Capital Expenditures in time 1 have an interaction effect on Firm Revenue in time 2. The greater the Capital expenditures, the more IT Expenditure will affect Firm Revenue.

Opposing hypotheses (direct effect hypotheses)

H2: IT Expenditure in time 1 has a more positive relationship than the interaction of IT Expenditure and Capital Expenditure on Firm Revenue in time 2

H3: Capital Expenditures in time 1 has a more positive relationship than the interaction of IT Expenditure and Capital Expenditure on Firm Revenue in time 2

These hypotheses are shown in Figure 2.

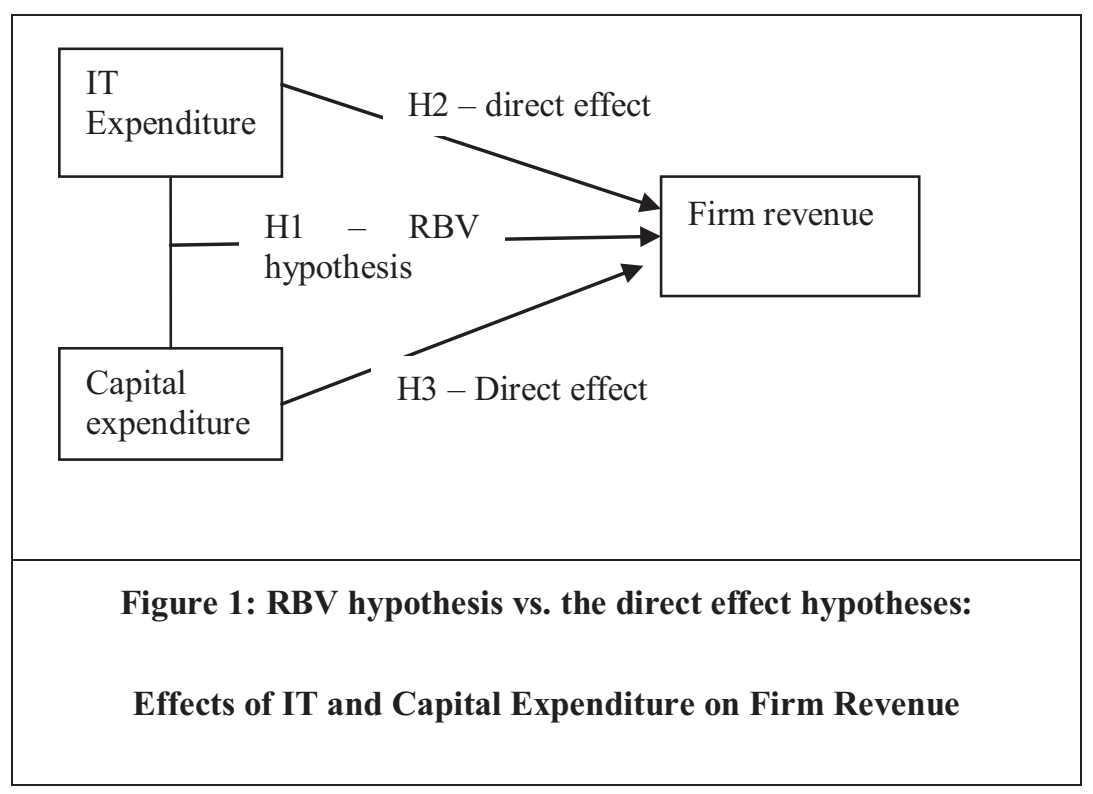

According to the resource-based view, resources that are valuable, rare, imperfectly imitable and have limited substitutability should result in an increase in the "rents" extracted by the firm (Barney, 1991). Therefore, if the combination of IT and Capital expenditures forms such a resource, it should result in an increase in Firm profit. In addition, according to Industrial Economics literature, improvements in firm revenue should result in a rise in firm profit. Therefore, the effects of IT and Capital Expenditures on revenue should be similar on firm profit as well. The RBV literature is more explicit about effects on firm profit. If any revenue gains are obtained directly from IT, these cannot translate into firm profit as IT is neither rare nor inimitable. Therefore, any revenue gains will be copied by other firms and the resulting profit gains will be competed away. Therefore, IT cannot directly provide a 
competitive advantage. Instead, any profit gains from IT can only accrue through an interaction with expenditure on other capital resources. Similar to firm revenue, we test the RBV hypothesis against the direct effect hypotheses on firm profit from IT. In this case we assume a longer time lag, as Firm Profit is more downstream that Firm Revenue, and therefore may take a longer time to be affected by firm expenditures.

Here, the RBV hypothesis is:

H4: IT Expenditure and Capital Expenditures in time 1 have an interaction effect on Firm Profit in time 3. The greater the Capital Expenditures, the more IT Expenditure will effect Firm Profit.

We test this against the opposing direct effect hypotheses:

H5: IT Expenditure in time 1 has a more positive relationship than the interaction effect IT Expenditure and Capital Expenditure with Firm Profit in time 3

H6: Capital Expenditures in time 1 has a more positive relationship than the interaction effect IT Expenditure and Capital Expenditure with Firm Profit in time 3

These hypotheses are shown in Figure 3.

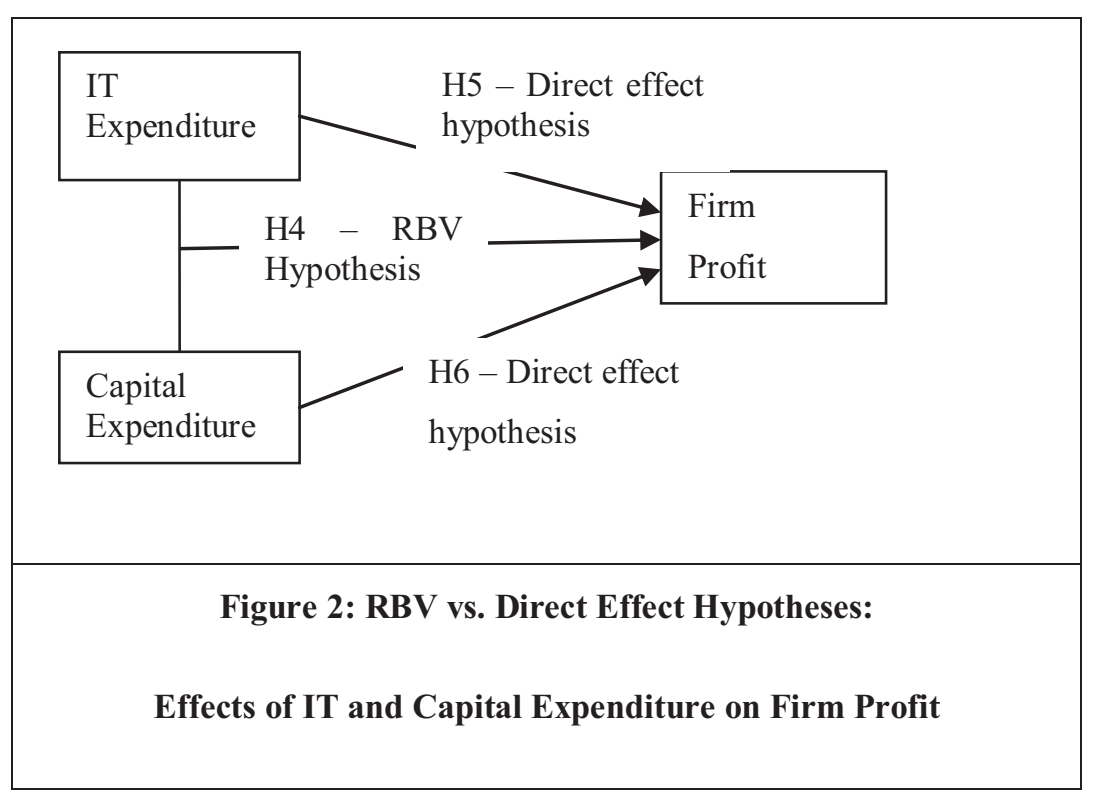




\section{Methodology}

The data was obtained from secondary sources, including IS budgets from InformationWeek magazine matched to firm level data from Standard \& Poor's Compustat database.

Data on IS budgets was gathered from InformationWeek magazine's website. InformationWeek magazine publishes an annual survey of 500 firms called the InformationWeek 500, in which it collects data on IT practices of various large firms in the United States, and ranks 500 of these firms based on the magazine editor's criteria for IT innovation. This data is collected through an extensive mail, phone, and fax survey of large firms, and their annual revenues are verified against public sources (InformationWeek, 2001). As part of this survey, data on IS Budgets is also collected from the respondents. The list is available online with archives going back to 1991, and for the surveys for 1991 through 1997, the data on IS Budgets is included as part of the online publication. We collected this data, along with the company's name and revenue for these seven years.

Standard \& Poor's Compustat database was used to collect firm-level data to measure revenue and performance. We matched the firms in the InformationWeek data set to those in the Compustat database. Initially, we attempted to match these firms by matching the name of the firm reported by InformationWeek to the most similar name in the Compustat database. However, this method was highly inaccurate due to name changes, mergers, and acquisitions. For example, "Monsanto" in the InformationWeek data set was matched to "Monsanto Co" in the Compustat database. However, these are two different companies - "Monsanto" as referred to in InformationWeek merged with Pharmacia in 2000 and took the Pharmacia name. Pharmacia, in turn, spun off its agriculture business and named it Monsanto, and the latter firm is the one in Compustat named "Monsanto Co". The firm that InformationWeek referred to is named "Pharmacia Corp" in the Compustat database. To ensure data integrity, we used revenue as a primary factor to match between the two data sets. This factor is more credible as InformationWeek verifies the company's revenue as it only includes US firms with annual revenue above the editor's criteria. As part of its prequalification application, InformationWeek asks for the organization's annual revenue for the most recent fiscal year as well as a source to confirm the revenue against (InformationWeek, 2007).

Therefore, we matched the revenue in InformationWeek against the revenue of the previous fiscal year in Compustat. As InformationWeek reported revenues rounded to the nearest million, we rounded the revenue in Compustat to the nearest million for matching purposes. We found an exact match between the two databases on 
revenue for a majority of the companies, providing us with strong confidence that the companies are indeed the same. If the names of the companies were not the same, the company's history was perused through the company's website, and public data sources. Data was retained only for companies that met both criteria, i.e., there had to be an exact match between the revenue reported in InformationWeek and Compustat, and if the names were not the same, the name change had to be verified through the public data sources used. The rigorous criteria used for matching increase the confidence in the integrity of our data set.

In operationalizing the variables for the study, we have to take into account correlations between the variables that may occur due to the size of the firms. Larger firms have more revenue, more profit and have greater resources as well as needs to spend more on Information Technology and Capital Expenditures. We remove this effect by operationalizing all the variables in the study as ratios to the number of employees of the firm in the time period. The independent variables IT and Capital Expenditures are therefore operationalized as IT Expenditure per employee and Capital Expenditure per employee, the dependent variables Firm Revenue is operationalized as revenues per employees and Firm Profit is operationalized as Profit per Employee.

We further refine our operationalization by addressing several concerns in using absolute dollar values in the variables. First, when IT investment is compared across industries and time, there is an inherent assumption that firms invest in similar information technologies across the sample, and therefore, their effects are comparable. However, the way IT is invested varies greatly across industry and over the years, grossly violating this assumption. Second, there are external industry and temporal effects that could affect the results of our data set. Third, the results may be sensitive to price deflators as IT depreciates at a faster rate than other assets and this differential depreciation can affect the results of this study. To take care of these issues, the independent, dependent and mediating variables are operationalized as relative to their competitors in each 2 digit sic code for each year. Therefore, the variables are operationalized as z scores for each industry for each year.

A time lag of one year was chosen between the independent, mediating, and dependent variables, as this was the smallest time lag allowed by the data set. A time lag of two years may be too long as that would mean a four year time lag between the independent and dependent variable, which may be too long to discern any significant relationships between the variables. In addition, with time lags longer than one year, we may miss important effects that take place in the intervening years. 
In addition to the industry and year, we include other variables that could possibly affect Firm Revenue and Firm Profit as control variables. This includes firm expenditure on other expenses: Research \& Development Expense and Advertising Expenses. These are operationalized similar to the other variables, as ratios of the number of employees and as z scores for the industry and the year.

\section{Results}

The data included 1285 usable data points. The sample is described in Table 1.

\begin{tabular}{|l|r|r|r|r|r|}
\multicolumn{7}{|c|}{ Table 1: Descriptive Statistics } \\
& Number & Minimum & \multicolumn{1}{c|}{ Maximum } & \multicolumn{1}{c|}{ Mean } & Std. Deviation \\
\hline IT Budget & 1285 & .105000 & 5105.006734 & $1.96104430 \mathrm{E} 2$ & $4.316181099 \mathrm{E} 2$ \\
\hline Capital Expenditure & 1160 & 5.31 & 10410.00 & 579.7959 & 897.72569 \\
\hline Revenue & 1285 & 248.60 & 153627.00 & 8298.0818 & 11223.30056 \\
\hline Employees & 1285 & .52 & 1140.00 & 41.6847 & 66.56219 \\
\hline Net Income & 1285 & -8101.00 & 22071.00 & 532.2152 & 1147.62672 \\
\hline
\end{tabular}

To test Hypothesis 1 to 3, we ran model 1 and 2 in Table 2. As we can see from this table the effects of the years and the industries are completely controlled for by our operationalization of the independent and dependent variables as z scores for each industry for each year. As hypothesized, Firm IT Intensity in year 1 is significantly and positively related to Firm Revenue in year $2(b=0.243, p<=0.001)$ in model $1 .$. In model 1, Capital Expenditures in year 1 also has a significant and positive relationship with Firm Revenue in year $2(b=0.384, p<0.001)$. However, when we add the interaction term to the model (Model 2), the interaction term is insignificant. Therefore, we do not find support for the RBV Hypothesis, Hypothesis 1. However, we find strong support for the opposing direct effect hypotheses, hypotheses 2 and 3, as IT Expenditure $(b=0.238, p<0.001)$ and Capital Expenditure $(b=0.401, p<0.001)$ still have direct effects on Firm Revenue in the presence of the interaction term. 
Table 2: Hypotheses 1 to 3

\begin{tabular}{|l|l|l|}
\hline DV = Firm Revenue & Model 1 & Model 2 \\
\hline Constant & 0.243 & -1.379 \\
\hline Year & 0.0 & 0.0 \\
\hline Industry & 0.0 & 0.0 \\
\hline Advertising expenses & $0.092^{* * *}$ & $0.238^{* * *}$ \\
\hline Research \& Development & $0.091 * *$ & $0.082^{* *}$ \\
\hline Expense & & \\
\hline IT Expenditure & $\mathbf{0 . 2 4 3 * * *}$ & $\mathbf{0 . 2 2 1} * * *$ \\
\hline Capital Expenditure & $\mathbf{0 . 3 8 4 * * *}$ & $\mathbf{0 . 4 0 1} * * *$ \\
\hline IT Expenditure x Capital & & $\mathbf{0 . 0}{ }^{\text {not significant }}$ \\
\hline Expenditure & & \\
\hline
\end{tabular}

We then test the Hypotheses 4-6 on the relationship between IT, Capital Expenditures and Firm Profit by running Models 3 and 4 (Table 3). We find that IT Expenditure in year 1 has a significant and positive relationship with Firm Profit in year $3(\mathrm{~b}=0.176, \mathrm{p}<0.001)$. We also find that Capital Expenditures have a significant and positive relationship with Firm Profit $(b=0.142, p<0.01)$. When the interaction term is added to the model (Model 4), the interaction term remains insignificant. Therefore, we fail to find support for the RBV hypothesis - Hypothesis 4. However, the opposing direct effect hypothesis are supported - Hypotheses 5 and 6, as the direct effects of IT and Capital Expenditures remain significant in the presence of the interaction term (IT Expenditure $\mathrm{x}$ Capital Expenditure)

Table 3: Testing Hypotheses 4-6

\begin{tabular}{|l|l|l|}
\hline DV = Firm Profit & Model 3 & Model 4 \\
\hline
\end{tabular}




\begin{tabular}{|l|l|l|}
\hline Constant & 0.340 & 0.672 \\
\hline Year & 0.0 & 0.0 \\
\hline Industry & 0.0 & 0.0 \\
\hline Advertising expenses & $0.145^{*}$ & $0.189 * *$ \\
\hline Research \& Development & $0.019^{*}$ & $0.011^{*}$ \\
\hline Expense & & \\
\hline IT Expenditure & $\mathbf{0 . 1 7 6 * * *}$ & $\mathbf{0 . 1 2 3} * * *$ \\
\hline Capital Expenditure & $\mathbf{0 . 1 4 2 * * *}$ & $\mathbf{0 . 1 6 4 * * *}$ \\
\hline IT Expenditure x Capital & & $\mathbf{0 . 0 5} \mathbf{5}^{\text {not significant }}$ \\
\hline Expenditure & & \\
\hline
\end{tabular}

These results are shown in Figures 3 and 4.

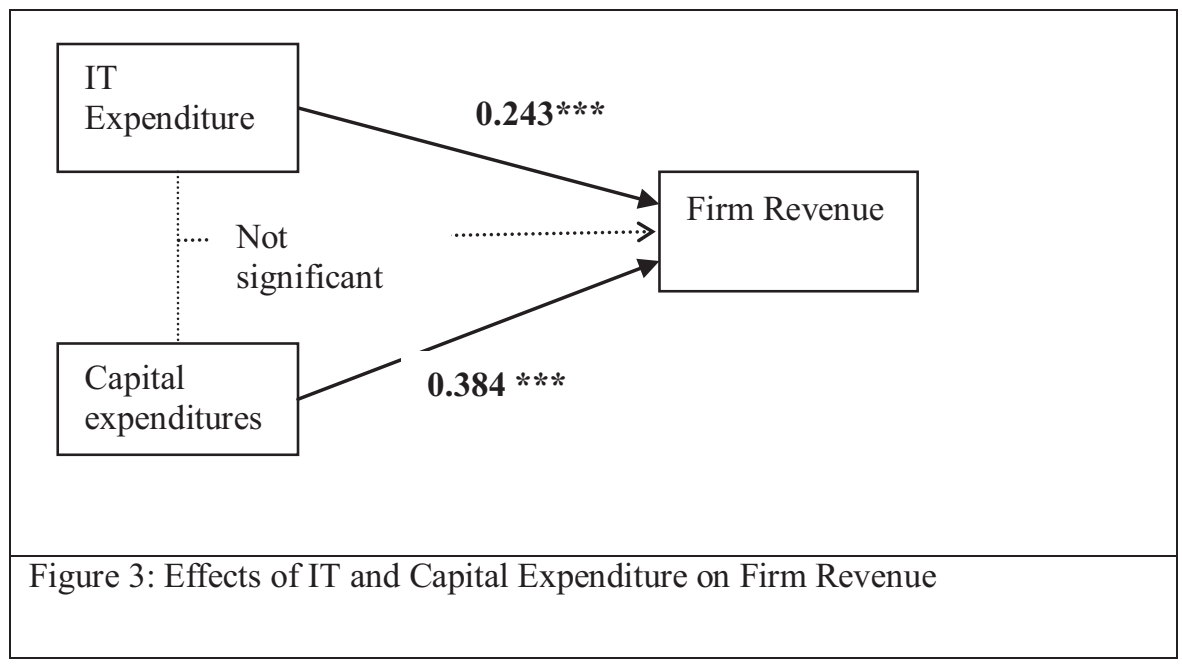




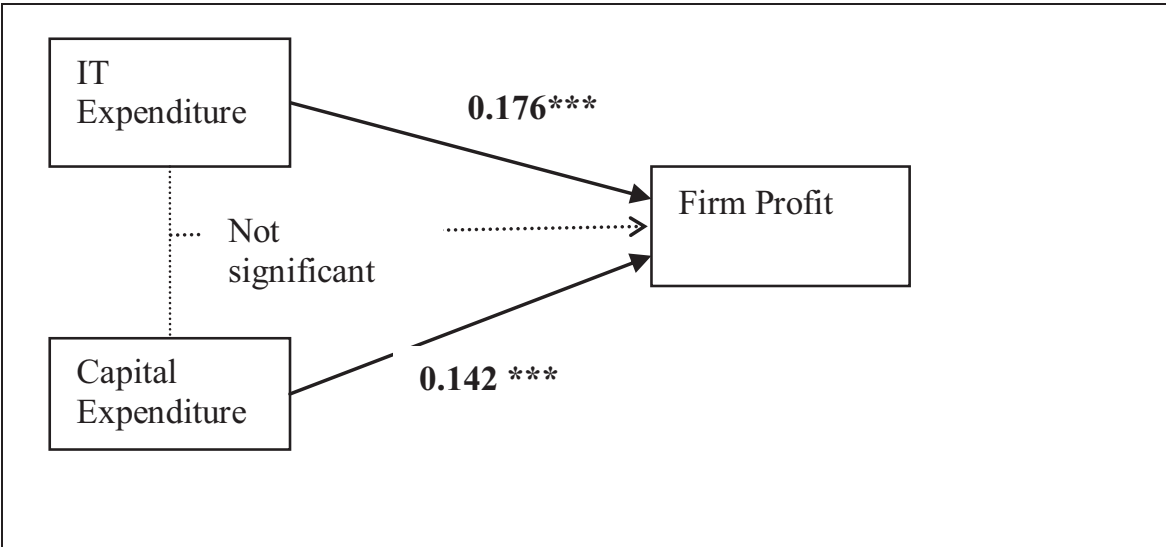

Figure 4: Effects of IT and Capital Expenditure on Firm Profit

\section{Discussion of Results}

In this paper, we tested the Resource-Based View of IT Business Value, in which the effects of IT Expenditure on firm performance are not direct effects, but instead, are a combination of the effects of IT Expenditure with expenditure on other resources. We find that contrary to the resource based view, the effects on both Firm Revenue and Firm Profit consist of direct effects of IT Expenditure and Capital Expenditures, and the interaction effects are insignificant. In table 4 we compare the tests of the two RBV hypotheses (H1 and H4, both unsupported) to the opposing direct effect hypotheses (H2, H3, H5 and H6, all four strongly supported)

\begin{tabular}{|l|l|}
\hline \multicolumn{2}{|c|}{ Table 4: Results of hypothesis tests } \\
\hline Hypothesis & Result \\
\hline RBV Hypotheses & Not Supported \\
\hline H1: IT Expenditure and Capital Expenditures in time 1 have an interaction & Not Supported \\
effect on Firm Revenue in time 2. The greater the Capital expenditures, the \\
more IT Expenditure will affect Firm Revenue.
\end{tabular}




\begin{tabular}{|c|c|}
\hline Opposing hypotheses (direct effect hypotheses) & Strongly Supported \\
\hline $\begin{array}{l}\text { H2: IT Expenditure in time } 1 \text { has a more positive relationship than the } \\
\text { interaction of IT Expenditure and Capital Expenditure on Firm Revenue in } \\
\text { time } 2\end{array}$ & Strongly Supported \\
\hline $\begin{array}{l}\text { H3: Capital Expenditures in time } 1 \text { has a more positive relationship than the } \\
\text { interaction of IT Expenditure and Capital Expenditure on Firm Revenue in } \\
\text { time } 2\end{array}$ & Strongly Supported \\
\hline $\begin{array}{l}\text { H5: IT Expenditure in time } 1 \text { has a more positive relationship than the } \\
\text { interaction effect IT Expenditure and Capital Expenditure with Firm Profit in } \\
\text { time } 3\end{array}$ & Strongly Supported \\
\hline $\begin{array}{l}\text { H6: Capital Expenditures in time } 1 \text { has a more positive relationship than the } \\
\text { interaction effect IT Expenditure and Capital Expenditure with Firm Profit in } \\
\text { time } 3\end{array}$ & Strongly Supported \\
\hline
\end{tabular}

These finding have important implications for the Resource Based View on IT Business Value. This view theorized that IT is pervasive; therefore it cannot be considered a rare or imperfectly imitable resource in accordance with the Resource Based View. These theories went further to suggest that it was the combination of IT with other investments that formed a rare and imperfectly imitable resource that can create value. However, we find that the effects of IT on Firm Revenue as well as Firm Profit are direct effects and not interaction effects. This could mean that IT Business value theories may need some additional postulations.

The first implication of this result is that IT might be a rare and imperfectly imitable resource for businesses. This may be because IT has an innate ability to unlock and foster the creation of knowledge. An IT system stores, transforms and communicates knowledge (Leonardi \& Bailey 2008). The knowledge-based theory of the firm (Grant 1996) extends the resource-based view to posit that knowledge is the firm's most valuable, rare, and inimitable resource, and hence, the most strategic. Firms exist to create knowledge and this knowledge explains sustained competitive advantage between firms. Firms selling products ranging from cement to consulting services 
understand this and are trying to become more knowledge-based (Zack, 2003). IT systems can unlock and create knowledge through their application in business processes. This may be because business use of IT is not as simple as buying a computer; instead, business use firm-specific knowledge to build or modify an IT system, resulting in an IT system with embedded firm-specific knowledge. This knowledge, in turn, provides the business some strategic value. Firms usually develop IT systems because they identify a firm-specific weakness or opportunity, for example, identifying processes that the firm performs inefficiently or ineffectively. Following this, they design IT systems that improve upon these processes by automating inefficient processes or reengineering ineffective processes. Even for Information Systems that utilize "out-of-the-box" or pre-packaged software, the business has to find a package that is suitable for its business processes, and after that, the package will have to be modified extensively to fit the organization. Therefore, considerable firm-specific knowledge is utilized in developing and utilizing an IT system first, firm specific knowledge about inefficient or ineffective processes, and after the new system is in place, firmspecific knowledge about the changed processes. Such firm-specific knowledge makes the IT system unique, and gives it rarity and imperfect imitability, making it a resource that can improve firm profit. In addition, Information Technology, by its very definition, involves processing and producing information, which can be used by knowledge workers to become more effective. Again, the information produced and knowledge work done is very firm-specific, making the IT system rare and imperfectly imitable, and enabling it to contribute to firm profit. Therefore, organizational IT by itself can be considered a valuable resource in line with the Resource-Based View.

While large ERP and SCM systems have considerable embedded knowledge, even the implementation of a smaller system like a client-server system for co-ordination causes changes in the organization that can improve knowledge creation and knowledge flows. For example, the apparel company, Guess? was wasting millions of dollars by making samples of clothing that never get sold (Wilde 1996). Out of every hundred samples made, only ten to twenty make it to market. A small change made in one department could cause a sample to miss a season. For example, if a designer changed a zipper to a button, it could cause a 14-week delay in production as that button could have a 14-week lead-time for orders. Guess? embedded this knowledge into a client-server system that coordinated between departments, causing designers to see the consequences of small changes in their design. In addition, the client server IT system allowed sales and marketing to see the new designs, and when they could be expected to be produced, helping them increase their sales efforts. Production could also communicate their changes to both design and sales. The knowledge flows between the departments can help with both the company's revenue 
and profit. For example, salespeople can suggest changes based on their contact with merchants and retailers. Production can see design specifics and start ordering immediately and get clothes on the market sooner. The knowledge flows also reduce the likelihood of incorrect product orders, incorrect quantity orders, and market delays, further helping both revenue and profit.

In addition, while considerable business value can be generated by automating processes, not all process automation requires substantial investments in complementary resources. For example, if marketing executives spent considerable portions of their day verifying customer and order information, and a new system automated this verification, it frees up the marketing executive to do more knowledge work, for example, spend more time with the customer and/or serve additional customers. Such automation may generate greater revenue and profit, without heavy investments in complementary resources.

Further, IT systems can outperform, or even replace capital expenditure due to its ability to create knowledge. For example, while other casinos spent tremendous capital on building palatial casinos with spectacular displays including volcanoes and recreations of famous structures, Harrah's casinos instead invested in an IT system (Loveman, 2003). This system gave them knowledge that enabled them to beat their competitor's capital expenditure: $82 \%$ of their revenues came from $26 \%$ of their clientele. This $26 \%$ was not the people who wore gold cufflinks and drove limousines that Harrah's and its competitors had spent tremendous amounts of capital trying to attract; they were mostly machinists, teachers and seniors. In addition, they found the industry strategy of giving out free rooms and free meals did not attract as much revenue as giving free chips or less wait times. Harrah's used this knowledge to develop a very different customer loyalty program than its competition, allowing their most loyal customers to never stand in lines for parking, eating, or checking-in. In addition, they knew how often each customer could be anticipated back and what incentives they respond to, so they could reach out to individual customers when they didn't show up and offer them exactly what they wanted to get them back. This enabled Harrah's casinos to grow by $14 \%$ while the rest of the market grew by $1 \%$. Harrah's knowledge gained from their IT system enabled them to outperform their competitors, who were spending billions of dollars in capital expenditure to build spectacular casinos (Loveman, 2003).

An alternative explanation could be that other factors may be missing from the study, especially ITBusiness Alignment (Chan, Huff, Barclay and Copeland 1997). In organizations with low IT-Business alignment, 
decisions on strategic uses of IT may be made in isolation with other business decisions. In this case, there may be low complementarities between IT Expenditure and Capital Expenditures. A measure of alignment may have to be taken into consideration while doing future studies on complementarities.

Another variable that could be considered in future studies is the level of Business Process Reengineering. Business Process Reengineering efforts, which require considerable expenditure in both IT and complementary resources, are fraught with risk and catastrophic failure, including bankruptcies. Businesses may therefore be shying away from BPR efforts and focusing on safer investments like process automation. In subsets of the population which are engaging in BPR, researchers may find a stronger interaction effect between IT and Capital Expenditure.

\section{Contributions}

This study makes an important contribution by testing the Resource Based View postulates on IT Business Value, that IT is not a rare and imitable resource that provides business value, but must be considered in combination with complementary resources that give IT value. This was presented in theory, but the moderating effects were not tested before, to the best of our knowledge. By testing this theory we are able to advance knowledge in this field and contribute to the cumulative tradition in IS. We find no support for the Resource Based View assertions that IT should be considered in combination and not alone, but instead, find that IT has direct effects on both Firm Revenue as well as Firm Profit. This indicates that IT can be considered a rare and inimitable resource that can provide value by itself, as IT can be part of a system that automates inefficient processes specific to a certain organization. Other organizations may have different processes that require a different system. This makes IT systems imperfectly imitable, and therefore becomes a valuable resource in accordance the Resource Based View (Barney, 1991).

We have also made very important contributions to research by improving upon the methodology of earlier studies by explicitly incorporating the theorized time lags between the independent and dependent variable, in order to better discern the effects. In addition, we address the methodological limitations of earlier studies that compared IT investment figures across industries and time, by converting the independent and dependent variables to $\mathrm{z}$ scores of their particular industry and year. 
For practice, this study has several implications for managers looking to gain competitive advantage from investments. Rather than investing in generic IT systems and trying to obtain uniqueness from investments in complementary resources, firms can try embedding firm-specific knowledge when designing or modifying their systems. In addition, firms should focus on implementing and using their systems to create knowledge. Such knowledge creating IT systems can outperform or even replace traditional capital expenditure, as the Harrah's example (Loveman, 2003) showed. Firms that gain better knowledge can outperform firms that invest lavishly in capital assets.

\section{Limitations and Future Directions}

The limitations of using secondary data in research apply to this study as well. Correlations between the data on IS budgets between different databases such as Harte-Hanks, Computerworld and IDG, improve our confidence in the dataset. Our confidence in InformationWeek's data is further increased as the data for InformationWeek is available publicly and has been used before in a number of published scholarly journal articles, including eminent IS journals. Matching between two datasets always has an increased risk of incorrect matches. We addressed this problem by matching between the two datasets on two criteria - the revenue as well as the name. The revenue reported by the company to InformationWeek is reportedly validated by InformationWeek against public sources, and the majority of companies had an exact match on revenue with the Compustat database. In addition, we left out all firms where we could not get an exact match on revenue between InformationWeek and Compustat, and we also removed all companies where we could not verify any name change through public company history. This increases our confidence that the firms matched are the same.

In addition, we have addressed a limitation of earlier studies, the sensitivity to price deflators. As IT depreciates at a faster rate than other capital, differential price deflators for IT and other dollar figures in the analysis need to be applied. Due to the difference in estimation of these deflators, the results may vary depending on the choice of price deflators. With our operationalization of the independent, dependent and mediating variables as $\mathrm{z}$ scores, the choice of price deflators will not affect the position of these companies relative to each other in that year, and therefore will not affect our results. 
There is a risk of firms appearing in different years may affect the results. However, as this dataset has been used before by other studies, this risk may be low.

Another limitation of using panel data is that it does not give us richer insights into the type of IT or capital expenditure used. However, case studies, surveys and field experiments may be able to give us additional insight into the specific type of IT used. In addition, future research can look at other variables that may affect the interaction model, such as Business-IS Alignment and Business Process Reengineering.

\section{References}

Barney, Jay B. (1991) Firm resources and sustained competitive advantage; Journal of Management 17(1) pp99-120

Bharadwaj, Anandhi S. (2000) A resource-based perspective on information technology capability and firm performance: An empirical investigation, MIS Quarterly, 24(1), pp. 169-196

Brynjolfsson, Erik (1993) The productivity paradox of information technology; Communications of the ACM, 36(12), pp 67-77

Carr, Nicholas G. (2003) IT Doesn't Matter,” Harvard Business Review, 81(5), pp.41-49

Chan, Yolande E., Huff, Sid L, Barclay Donald W., Copeland, Duncan G (1997) Business strategic orientation, information systems strategic orientation and strategic alignment; Information Systems Research, 8(2), p125150

Grant, Robert M (1996) Toward a knowledge-based theory of the firm; Strategic Management Journal; 17 (Winter Special Issue); pp. 109-122

Hitt, Lorin M.; Brynjolfsson, Erik (1996) Productivity, business profitability and consumer surplus: Three different measures of information technology value; MIS Quarterly 22(2), pp121-142

InformationWeek (2001) Methodology: How We Picked Our IT Innovators, http://www.informationweek.com/story/IWK20010916S0010;jsessionid=1CGCWJG1OCDXIQSNDLRCKH0 CJUNN2JVN, current as of July 12006

InformationWeek (2007) "InformationWeek 5002007 prequalification application" Retrieved on June 12th 2007 from http://cmp.inquisiteasp.com/cgi-bin/qwebcorporate.dll?idx=CHH444 
Leavitt, Harold J.; Whisler, Thomas L. (1958) Management in the 1980's; Harvard Business Review, 36(6), pp. 4148

Leonardi, Paul M \& Bailey, Diane E.(2008) Transformational technologies and the creation of new work practices: making implicit knowledge explicit in task-based offshoring, MIS Quarterly, 32(2) pp. 411-436.

Loveman, Gary (2003) Diamonds in the data mine; Harvard Business Review, May 2003, pp 109-113.

Mahmood, Mo Adam; \& Mann, Gary J. (1993) Measuring the organizational impact of information technology investment: An exploratory study; Journal of Management Information Systems; 10(1) pp. 97-122

Malone, Thomas W., \& Rockart John F. (1991) Computers, networks, and the corporation, Scientific American, 265(3), pp 128-136

Melville, Nigel; Kraemer, Kenneth; Gurbaxani, Vijay (2004) Review: Information technology and organizational performance: An integrative model of IT business value. MIS Quarterly; 28(2), pp. 283-322

Nicolaou, Andreas I. (2004) Firm performance effects in relation to the implementation and use of enterprise resource planning systems. Journal of Information Systems, Fall2004, 18(2), p79-105

Peslak, Alan R (2003) A firm level study of information technology productivity using financial and market based measures; Journal of Computer Information Systems, 43(4), pp. 72-80

Ranganathan, C. \& Brown, Carol V. (2006) ERP investments and the market value of firms: Towards an understanding of influential ERP project variables, Information Systems Research; 17(2) pp 145-161

Tanriverdi, Huseyin (2006) Performance effects of information technology synergies in multibusiness firms, MIS Quarterly, 30(1) pp 57-77

Wilde, Candee (1996) No more Guess? work; InformationWeek, September $23^{\text {rd }}, 1996$.

Zack, Michael, H. (2003) Rethinking the knowledge based-organization, MIT Sloan Management Review, 44(4), pp $67-71$

Zhang, Michael J. (2007) Assessing the performance impacts of information systems from the resource-based perspective: An empirical test of the indirect effect of IS; Journal of Business Strategies, 24(2) pp 141-164 